\title{
The Distribution and Accessibility of Assisted Reproductive Technology Clinics in Mainland China From 2006 to 2018: a Population-based Retrospective Study
}

\section{Yi Ma}

National Center for Women's and Children's Health, China CDC https://orcid.org/0000-0001-6255-7099

\section{Fu Bai}

National Center for Women's and Children's Health, China CDC

\section{Lina Gao}

National Center for Women's and Children's Health, China CDC Yanjun Fan ( $\nabla$ merrytang81@163.com )

National Center for Women's and Children's Health, China CDC

\section{Research}

Keywords: Assisted reproductive technology, accessibility, equity, geographic distribution

Posted Date: December 8th, 2020

DOl: https://doi.org/10.21203/rs.3.rs-120639/v1

License: (c) (1) This work is licensed under a Creative Commons Attribution 4.0 International License.

Read Full License 


\section{Abstract}

Background: Infertility is a global health problem that carries a high social and economic burden. Assisted reproductive technology (ART) has been developed in mainland China for over 30 years. We aimed to evaluate the accessibility and equity of distribution of ART facilities in mainland China from 2006 to 2018 , and quantify the population with reduced geographic access to ART services.

Method: A retrospective study was conducted to describe the trend and analyze the equity of distribution of ART clinics in 2006, 2012, and 2018. Coverage rates were calculated by city and by population. Size of population living in areas with different regional choice of ART services was identified. The Gini coefficients were calculated to measure the equity of the distribution of ART clinics.

Results: There were 85 ART clinics (not counting artificial insemination clinics) in mainland China in 2006, 356 in 2012, and 498 in 2018 . The coverage rate of ART clinics was increased significantly (PV 0.05). Eastern China had the most extensive coverage, followed by the central region, while the western region had the least coverage ( $P \llbracket 0.05)$. At the end of 2018, 171.4 million people in 47 cities had no access to in vitro fertilization (IVF) clinics, but had access to at least one artificial insemination clinic in their own cities. There were still 354.9 million people (25.4\% of the population) living in 148 cities without any ART clinics, indicating that $\mathbf{1 7 9 . 5}$ million people of reproductive age had no access to ART services. The Gini coefficients for the distribution of IVF clinics in mainland China in 2006, 2012, and 2018 were $0.389,0.275$ and 0,267 respectively, and for the distribution of ART clinics in 2012, and 2018 were 0.222 and 0.213 .

Conclusion(s): The accessibility of ART clinics in mainland China increased significantly in the twelve years to 2018. The equity of distribution of ART clinics was quite balanced over the country. However, underserved areas still exist, especially in the western region, which has spurred more targeted policies and cost-effective measures to improve the accessibility and availability of ART services in such areas.

\section{Introduction}

Infertility is a global health problem that carries a high social and economic burden, especially where access to care is lacking ${ }^{[1-4]}$. Unequal distribution and improper allocation can result in the loss of resources and increase of health costs for the patients, the health system, and the whole society ${ }^{[5]}$. Distance, cost, health literacy, ethnicity, and expertise are important factors that influence whether and how patients seek health care ${ }^{[6-9]}$. As assisted reproductive technology (ART) involves multiple consultative appointments, complex diagnosis, invasive therapies and partner-based care, disparity of burden on patients with infertility could be greatly magnified. WHO and many fertility organizations have devoted great efforts to improving access to infertility care and reducing inequalities within and between countries ${ }^{[4,6,10]}$. Recent publications by the American Society of Reproductive Medicine (ASRM) and the Centers for Disease Control and Prevention (CDC) advocate eliminating or reducing the disparities in access to infertility care, especially disparities between different races, socioeconomic classes, and 
regions ${ }^{[6]}$. China has a vast territory, and inequality of health care exists not only between provinces or regions, but also exists at the intra-province level ${ }^{[11]}$.

ART has been developed in mainland China for over 30 years since the first test tube baby was born in Beijing in 1988, and is being applied more and more widely ${ }^{[12]}$. The first regulation of ART in mainland China was promulgated in February 2001, which stipulated that medical institutions that carry out ART treatment should be licensed and monitored by the National Health Commission (NHC). ART was classified as artificial insemination with husband's semen (AIH), artificial insemination with donor's semen (AID), in vitro fertilization and embryo transfer (IVF-ET), intracytoplasmic sperm injection (ICSI), and preimplantation genetic testing (PGT). In 2007, the NHC transferred the right of licensing to local Health Commissions. To strengthen the management of ART, the NHC has issued a series of supplementary regulations and documents since 2013, including supplementary provisions on approval requirements and guiding principles for planning the allocation of ART clinics ${ }^{[13-15]}$. The number of clinics in each province is prelimited by the government. One of the optional criteria is: one ART clinic should be set up for every 3 million permanent residents in a province.

In this context, this study attempts to summarize and describe the allocation and development of ART facilities in mainland China in recent years, evaluate the equity of accessibility of ART facilities in different periods, and identify and quantify the populations with reduced access to ART services.

\section{Methods}

\section{Data}

NHC has published the list of approved ART clinics in mainland China six times: in 2004, 2006, 2007, 2012,2016 and $2018^{[16]}$. As ART management strategies have changed at different development stages, the lists of 2006, 2012 and 2018 were selected to form a longitudinal cohort of clinics. The types of ART service which were licensed to the clinics and the addresses of clinics in each year were extracted and pooled by city, by province and by region. It must be noted however that the list of 2006 did not include clinics which only carried out AlH treatment. Moreover, three clinics only providing AID treatment in 2006 were excluded from analysis.

The data on population of each city in 2006, 2012 and 2018 were collected from the publicly available authoritative materials, including China Statistics Yearbook and National Economic and Social Development Statistics Bulletins of 31 provinces. Here the 31 provinces means 23 provinces, plus four province-level municipalities, and four autonomous regions, but not including Hong Kong, Macao or Taiwan.

\section{Data analysis}

A retrospective study was conducted to describe the trend and analyze the equity of distribution of ART clinics in 2006, 2012, and 2018. Given data availability, we used the city as our statistical unit. There were 
333 prefecture-level cities and 4 provincial-level municipalities (Beijing, Tianjin, Shanghai, and Chongqing) in mainland China ${ }^{[17]}$. The distribution of ART clinics was summarized into two levels: at provincial level for the 31 provinces and at regional level using three regions - eastern, central, and western. The three regions were classified in accordance with the terrain (Fig. 1).

Regional choice was defined in five levels as: city with no ART clinic, city with a single artificial insemination (Al) clinic, city with multiple Al clinics but without IVF clinic, city with a single IVF clinic, or city with multiple IVF clinics. In 2018, there were also four clinics allocated in counties directly under the provincial government. These were excluded in our analysis. We described accessibility by calculating the proportion of population with each regional choice.

The Gini coefficient is widely used to measure the balance of the distribution of health resources. It was calculated to analyze the equity in distribution of ART clinics in the whole country and in each region. The Gini coefficient has a range from 0 to 1 . The closer it is to 1 , the greater the inequity in distribution of resources it represents: $\leq 0.2$ absolute equality, $0.2 \sim 0.35$ relatively balanced, $0.35 \sim 0.5$ comparatively unequal distribution, $0.5 \sim 0.7$ very uneven, and so on ${ }^{[18-21]}$. The equation for calculating the Gini coefficient is as follows:

$$
G=1-\sum_{i=0}^{n-1}\left(Y_{i+1}+Y_{i}\right)\left(X_{i+1}-X_{i}\right)
$$

where $Y_{i}$ is the cumulative percentage of ART/IVF clinics in each province, $X_{i}$ is the cumulative percentage of population (sorted by variable) of each province, and $n$ is the number of provinces.

\section{Statistical methods}

Regional choice of each city was plotted graphically using ArcMap 10.2 bound by city regions. Coverage rates among groups were compared using the Chi-Square test. Due to heterogeneity of variance, medians among groups were compared using Kruskal-Wallis rank sum test. These two analyzes were performed by SPSS 22. The Gini coefficients were calculated by Excel 2016.

\section{Results}

\section{General characteristics}

In mainland China, ART includes AI, IVF and various derived techniques, however the data about the clinics which only offer Al services was lacking in 2006. To measure the precise trend of the ART clinics development, we compare the growth rate of IVF clinics from 2006 to 2018 and the growth rate of all ART clinics from 2012 to 2018 respectively. There were 85 clinics that offered IVF technology in mainland China in 2006, 217 in 2012, and 375 in 2018 respectively. The growth rate (155.3\%) in the number of IVF clinics in the first stage (2006 to 2012) was faster than the equivalent growth rate (72.8\%) in the second 
stage (2012 to 2018). The national total of ART clinics in mainland China increased from 356 in 2012 to 498 in 2018 , with an increase rate of $39.9 \%$ (Table 1 ).

Table 1

Number and growth rates of ART/IVF clinics in 2006, 2012 and 2018

\begin{tabular}{|lllllllll|}
\hline & \multicolumn{1}{l}{ IVF clinics } & & \multicolumn{5}{c|}{ ART clinics } \\
\cline { 2 - 10 } & $\mathbf{2 0 0 6}$ & $\mathbf{2 0 1 2}$ & $\begin{array}{l}\text { 2006-2012 } \\
\text { Growth rate (\%) }\end{array}$ & $\mathbf{2 0 1 8}$ & $\begin{array}{l}\text { 2012-2018 } \\
\text { Growth rate } \\
(\%)\end{array}$ & $\mathbf{2 0 1 2}$ & $\mathbf{2 0 1 8}$ & $\begin{array}{l}\text { 2012- } \\
\text { 2018 } \\
\text { Growth } \\
\text { rate (\%) }\end{array}$ \\
\hline Eastern & 46 & 121 & 163.0 & 210 & 73.6 & 191 & 264 & 38.2 \\
\hline Central & 15 & 48 & 220.0 & 92 & 91.7 & 105 & 139 & 32.4 \\
\hline Western & 24 & 48 & 100.0 & 73 & 52.1 & 60 & 95 & 58.3 \\
\hline Total & 85 & 217 & 155.3 & 375 & 72.8 & 356 & 498 & 39.9 \\
\hline
\end{tabular}

\section{Accessibility analysis}

In 2006, 40 (11.9\%) cities had IVF clinics, covering a population of 291.2 million (22.5\% of the national population). By the end of 2018,142 cities ( $42.1 \%$ of the number of cities nationally) had IVF clinics, covering a population of 870.2 million (62.3\% of the national population). 189 cities (56.1\% of the number of cities) had ART clinics, covering 1045.0 million people(74.8\% of the national population). The coverage rates calculated by city and by population in mainland China and each region increased significantly in the twelve years ( $\mathrm{Q} \llbracket 0.05)$, although there was no statistical difference in the coverage rate of ART clinics calculated by city in central China between 2012 and 2018(Table 2). Overall, the eastern region had the most extensive coverage, followed by the central region, and the western region, which had the least coverage (Table 2, Fig. 2). The differences in distribution of ART and IVF clinics in three regions were statistically significant $(P<0.05)$. 
Table 2

The city and population coverage rates of ART/IVF clinics in 2006, 2012 and 2018

\begin{tabular}{|c|c|c|c|c|c|}
\hline & & 2006 IVF (\%) & $\begin{array}{l}2012 \text { IVF } \\
(\%)\end{array}$ & 2018 IVF (\%) & $\begin{array}{l}P^{*} \text { for } \\
\text { trend }\end{array}$ \\
\hline \multirow[t]{5}{*}{ Cities covered } & All & $40(11.9)$ & $94(27.9)$ & $142(42.1)$ & 0.000 \\
\hline & Eastern & $21(20.6)$ & $54(52.9)$ & $72(70.6)$ & 0.000 \\
\hline & Central & $8(7.7)$ & 20(19.2) & $42(40.4)$ & 0.000 \\
\hline & Western & $11(8.4)$ & $20(15.3)$ & $28(21.4)$ & 0.013 \\
\hline & $\begin{array}{l}\mathrm{P}^{\star \star} \text { for } \\
\text { regions }\end{array}$ & 0.005 & 0.000 & 0.000 & \\
\hline \multirow{6}{*}{$\begin{array}{l}\text { Population in million } \\
\text { covered }\end{array}$} & Total & 291.2(22.5) & 628.1(46.6) & $870.2(62.3)$ & 0.000 \\
\hline & Eastern & $162.5(31.4)$ & $385.7(69.1)$ & $486.9(83.8)$ & 0.000 \\
\hline & Central & 47.7(11.4) & 121.1(28.5) & $229.5(52.6)$ & 0.000 \\
\hline & Western & $81.0(22.5)$ & 121.3(33.3) & $156.0(41.1)$ & 0.000 \\
\hline & $\begin{array}{l}\mathrm{P}^{* \star} \text { for } \\
\text { regions }\end{array}$ & 0.000 & 0.000 & 0.000 & \\
\hline & & $2006 \mathrm{ART}(\%)^{\star \star \star}$ & 2012ART(\%) & 2018ART(\%) & $\begin{array}{l}\mathrm{P}^{*} \text { for } \\
\text { trend }\end{array}$ \\
\hline \multirow[t]{5}{*}{ Cities covered } & Total & -- & $145(43)$ & $189(56.1)$ & 0.001 \\
\hline & Eastern & - & $72(70.6)$ & $85(83.3)$ & 0.031 \\
\hline & Central & - & $51(49.0)$ & $65(62.5)$ & 0.051 \\
\hline & Western & - & $22(16.8)$ & $39(29.8)$ & 0.013 \\
\hline & $\begin{array}{l}\mathrm{P}^{\star \star} \text { for } \\
\text { regions }\end{array}$ & - & 0.000 & 0.000 & \\
\hline \multirow{2}{*}{$\begin{array}{l}\text { Population in million } \\
\text { covered }\end{array}$} & Total & - & $841.0(62.4)$ & $1045.0(74.8)$ & 0.000 \\
\hline & Eastern & - & $460.0(82.4)$ & $535.1(92.1)$ & 0.000 \\
\hline
\end{tabular}

* To compare the coverage rates of ART/IVF clinics in 2006, 2012, and 2018 using Chi-Square test. Pvalue less than 0.05 is statistically significant.

** To compare the coverage rates of ART/IVF clinics in Eastern, Central, and Western China using ChiSquare test. $P$-value less than 0.05 is statistically significant.

*** A list of clinics which only carried out AlH treatment was not available in 2006.

**** 0 cells have an expected count of less than 5 . 


\begin{tabular}{|c|c|c|c|c|}
\hline & 2006 IVF (\%) & $\begin{array}{l}2012 \text { IVF } \\
(\%)\end{array}$ & 2018 IVF (\%) & $\begin{array}{l}P^{*} \text { for } \\
\text { trend }\end{array}$ \\
\hline Central & -- & 249.1(58.6) & $317.0(72.7)$ & 0.000 \\
\hline Western & -- & $131.9(36.2)$ & 192.8(50.8) & 0.000 \\
\hline $\begin{array}{l}P^{* \star} \text { for } \\
\text { regions }\end{array}$ & -- & 0.000 & 0.000 & \\
\hline \multicolumn{5}{|c|}{$\begin{array}{l}\text { * To compare the coverage rates of ART/IVF clinics in 2006, 2012, and } 2018 \text { using Chi-Square test. P- } \\
\text { value less than } 0.05 \text { is statistically significant. }\end{array}$} \\
\hline \multicolumn{5}{|c|}{$\begin{array}{l}\text { ** To compare the coverage rates of ART/IVF clinics in Eastern, Central, and Western China using Chi- } \\
\text { Square test. P-value less than } 0.05 \text { is statistically significant. }\end{array}$} \\
\hline \multicolumn{5}{|c|}{ *** A list of clinics which only carried out AlH treatment was not available in 2006.} \\
\hline \multicolumn{5}{|c|}{ **** 0 cells have an expected count of less than 5 . } \\
\hline
\end{tabular}

In 2018, in addition to the four municipalities (Beijing, Tianjin, Shanghai and Chongqing), in the eastern region, coverage rates of ART clinics in Jiangsu, Hebei and Zhejiang provinces reached $100 \%$; ART clinics in Shandong, Fujian and Guangdong provinces covered more than $90 \%$ of the population; Hainan province had the lowest coverage rate (36.3\% of the population). In the central region, Jiangxi Province had the highest coverage ( $88.8 \%$ of the population), while Anhui Province had the lowest coverage (52.3\% of the population). In the western region, Guangxi Province had the highest coverage $(85.9 \%$ of the population), while Shaanxi $(25.9 \%)$, Tibet $(16.1 \%)$ and Gansu Provinces $(14.2 \%)$ had the lowest coverage by population (Supplemental table 1). Given the standard of one ART clinic per 3 million people, in 2018, 10 out of 11 provinces in the eastern region, 3 out of 8 provinces in the central region and 3 out of 12 provinces in the western region met the standards. The ratio of ART clinics to the population in Anhui, Gansu, Sichuan, and Shaanxi provinces was 1 to 5.7-7.7 million, which was far below the standard.

As illustrated in Table 3, 576.3 million people in 73 cities had access to multiple IVF clinics in 2018, compared to 208.0 million people in 23 cities in 2006. 171.4 million people in 47 cities had no access to an IVF clinic, but had access to at least one Al clinic. By 2018, there were still 354.9 (25.4\%) million people living in 148 cities without any ART clinic. Using the 2010 Population Census Data of China, our calculations indicate that almost 179.5 million reproductive-age (ages 20-49 years) people (91.1 million male and 88.3 million female) had no access to any ART services. 
Table 3

ART health care availability for the Chinese mainland population in 2006, 2012 and 2018

\begin{tabular}{|c|c|c|c|c|c|c|}
\hline & $\begin{array}{l}\text { Level of } \\
\text { patient } \\
\text { access }\end{array}$ & $\begin{array}{l}\text { Total } \\
\text { clinics (\%) }\end{array}$ & Cities (\%) & $\begin{array}{l}\text { Median of } \\
\text { population per city, } \\
\text { in million, (range) }\end{array}$ & $\begin{array}{l}\text { Population } \\
\text { represented, in } \\
\text { million, (\%) }\end{array}$ & $\mathrm{P}^{*}$ \\
\hline \multirow[t]{3}{*}{2006} & $\begin{array}{l}\text { Without any } \\
\text { regional IVF } \\
\text { clinics }^{\star *}\end{array}$ & 0 & 297(88.1) & $3.0(0.1-10.7)$ & $1004(77.5)$ & 0.000 \\
\hline & $\begin{array}{l}\text { Available of } \\
\text { IVF clinic but } \\
\text { no choice }\end{array}$ & $17(20.0)$ & $17(5.0)$ & $5.6(1.9-9.5)$ & $83.2(6.4)$ & \\
\hline & $\begin{array}{l}\text { Multiple IVF } \\
\text { clinics }\end{array}$ & 68(80.0) & $23(6.8)$ & $9.8(3.8-31.0)$ & $208.0(16.1)$ & \\
\hline \multirow[t]{5}{*}{2012} & $\begin{array}{l}\text { Without any } \\
\text { regional ART } \\
\text { clinics }\end{array}$ & 0 & 192(57.0) & $2.4(0.1-8.8)$ & $506.9(37.6)$ & 0.000 \\
\hline & $\begin{array}{l}\text { Available of } \\
\text { Al clinic but } \\
\text { no choice }\end{array}$ & $39(11.0)$ & $39(11.6)$ & $3.9(1.2-8.2)$ & $147.6(10.9)$ & \\
\hline & $\begin{array}{l}\text { Multiple Al } \\
\text { clinics but no } \\
\text { access to IVF }\end{array}$ & $26(7.3)$ & $12(3.6)$ & $4.8(3.0-9.5)$ & $65.3(4.8)$ & \\
\hline & $\begin{array}{l}\text { Available of } \\
\text { IVF clinic but } \\
\text { no choice }\end{array}$ & $81(22.8)$ & $53(15.7)$ & $4.9(1.9-10.6)$ & $283(21.0)$ & \\
\hline & $\begin{array}{l}\text { Multiple IVF } \\
\text { clinics }\end{array}$ & $210(59.0)$ & $41(12.2)$ & $7.7(2.3-31.0)$ & $345(25.6)$ & \\
\hline \multirow[t]{4}{*}{2018} & $\begin{array}{l}\text { Without any } \\
\text { regional ART } \\
\text { clinics }\end{array}$ & 0 & $148(43.9)$ & $2.1(0.1-7.3)$ & $354.9(25.4)$ & 0.000 \\
\hline & $\begin{array}{l}\text { Available of } \\
\text { Al clinic but } \\
\text { no choice }\end{array}$ & $41(8.3)$ & $41(12.2)$ & $2.9(1.2-8.8)$ & $140.1(10.0)$ & \\
\hline & $\begin{array}{l}\text { Multiple Al } \\
\text { clinics but no } \\
\text { access to IVF }\end{array}$ & $12(2.4)$ & $6(1.8)$ & $4.9(2.2-8.2)$ & $31.3(2.2)$ & \\
\hline & $\begin{array}{l}\text { Available of } \\
\text { IVF clinic but } \\
\text { no choice }\end{array}$ & $89(18.0)$ & $69(20.5)$ & $4.2(0.6-10.0)$ & $293.9(21.0)$ & \\
\hline
\end{tabular}

* To compare the medians of population among different levels of ART/IVF clinic accessibility in 2006, 2012, and 2018 using Kruskal-Wallis rank sum test.

** List of clinics which only carried out AlH treatment were not available in 2006. 


\begin{tabular}{|c|c|c|c|c|c|}
\hline $\begin{array}{l}\text { Level of } \\
\text { patient } \\
\text { access }\end{array}$ & $\begin{array}{l}\text { Total } \\
\text { clinics (\%) }\end{array}$ & Cities (\%) & $\begin{array}{l}\text { Median of } \\
\text { population per city, } \\
\text { in million, (range) }\end{array}$ & $\begin{array}{l}\text { Population } \\
\text { represented, in } \\
\text { million, (\%) }\end{array}$ & $\mathbf{P}^{\prime}$ \\
\hline $\begin{array}{l}\text { Multiple IVF } \\
\text { clinics }\end{array}$ & $352(71.3)$ & $73(21.7)$ & $7.3(2.3-31.0)$ & $576.3(41.3)$ & \\
\hline \multicolumn{6}{|c|}{$\begin{array}{l}\text { * To compare the medians of population among different levels of ART/IVF clinic accessibility in } \\
2006,2012 \text {, and } 2018 \text { using Kruskal-Wallis rank sum test. }\end{array}$} \\
\hline \multicolumn{6}{|c|}{ ** List of clinics which only carried out AlH treatment were not available in 2006.} \\
\hline
\end{tabular}

In 2006, 2012 and 2018, the median population of cities with multiple IVF clinics was 9.8 million, 7.7 million and 7.3 million respectively, which suggest a significant improvement in accessibility. It shows that better ART services were distributed in the cities with larger population (Table 3).

\section{Equity analysis}

The Gini coefficients for the distribution of IVF clinics in mainland China in 2006, 2012, and 2018 based on population index were $0.389,0.275$ and 0,267 respectively (Fig. 3 ). The Gini coefficients for the distribution of ART clinics in mainland China in 2012, and 2018 based on population index were 0.222 and 0.213 respectively. From 2006 to 2012, the Gini coefficient for the distribution of IVF clinics in the eastern and central regions declined greatly. As for the distribution of ART clinics in the three regions in 2012 and 2018, the Gini coefficient changed only slightly.

\section{Discussion}

In this study we investigated trends of allocation of ART clinics allocation over the previous twelve years in mainland China. We also evaluated the equity of distribution of ART clinics. This analysis indicates that the number and accessibility of ART clinics in mainland China increased significantly from 2006 to 2018. In 2018, the number of ART clinics in China was almost at the same level as some developed countries, for example, 502 clinics in the US ${ }^{[22]}$ and 607 clinics in Japan ${ }^{[23]}$. The Gini coefficients showed that from 2006 to 2018, the equity of distribution of ART clinics improved greatly, reaching relative balance overall. The distribution of IVF clinics in eastern China and ART clinics in eastern China and central China reached absolute equality.

Since the promulgation of policies on authorization and allocation of ART clinics in 2013, the growth rate of ART clinics in China has slowed down. It is required that authorization of a new ART service must refer to the evaluation by a randomly composed national experts group, and assisted reproductive clinics must operate Al for more than one year before they can apply for IVF/ICSI technology, and operate IVF/ICSI for at least five years before they can apply for $\mathrm{PGT}^{[2]}$. As the total number of clinics gradually approached the upper levels of the plan, in the second stage (2012-2018) eastern China and central China mainly 
expanded IVF and derivative technologies within existing ART clinics. In three regions the number of ART clinics without IVF authorization in western China grew fastest from 2012 to 2018, illustrating that there were still more potentialities for development in western China.

Despite ART becoming a mainstream medical intervention for infertility, the accessibility of ART clinics in western China was still at a low level in 2018, which implied several factors. On the one hand, the previous analysis had indicated that ART clinics were more likely distributed in cities with large population, which is consistent with ART clinic distribution in the United State ${ }^{[11,24]}$. Many provinces in western China have the geographical characteristics of vast territory and sparse population, and much of the territory is at high altitude. Thus access to clinics is difficult for many people. On the other hand, the stringent accreditation requirements for ART clinics in China mean that the cost is high ${ }^{[25]}$. The high investment needed for facility construction, advanced equipment, professional technology, and human resources could be intangible impediments efforts by local government to establish ART clinics. In China, infertility treatments are not yet subsidized through the national health insurance scheme. Residents' income determine whether they are willing or able to make full use of ART. A previous study in Australia showed that women in the disadvantaged social-economic class had a $6-16 \%$ reduction in access to ART treatment, and women living in regional and remote areas had a $12 \%$ reduction. When the out of pocket cost of ART treatment was increased by one third there would be a $21-25 \%$ decrease in access to treatment ${ }^{[26,27]}$. The overall economic development of western China, lagging behind that of the eastern and central regions, has resulted in the shortage of both the supply and utilization of ART services.

In the future regional allocation, the geographical and social-economic characteristics of western China should be taken into consideration. Basic infertility diagnosis and treatment technologies, such as prevention and screening of impaired fecundity, reproductive health education, Al and other cost-effective treatments should be given priority. In addition, local monitoring and tele-medicine can be used to relieve some of the cost burden for patients in areas without advanced ART services. In the second health care system reform since 2010, the Chinese government has attempted to resolve the disparity of medical resources by grouping medical institutes of different levels into a regional medical consortium ${ }^{[28]}$. Establishing and promoting dual referral systems and appointments, data browsing between hospitals and regional information systems, and remote consultation services are part of the reform goals $[29,30]$. These changes will offer opportunities and raise a promising prospect for improving the availability and accessibility of ART treatment.

Looking specifically at the provincial level, out of the 31 provinces Anhui, Gansu, Sichuan, Shaanxi, and Tibet had the least accessibility to ART clinics, while the distribution characteristics of ART clinics differed. Anhui and Sichuan are two of the provinces with large population, but the number of ART clinics is less than half of that in other provinces with the same population size. Shaanxi and Gansu province, with middle-level population size, had a relatively small number of ART clinics, and all the ART clinics were centrally located in the provincial capital. In future, government could consider increasing the number of ART institutions for the above four provinces in order to improve the accessibility of services. 
Moreover, attention should be paid to balancing the distribution of newly established institutions within the province.

Tibet is a special case. In Tibet, with an average altitude of more than 4000 meters, $95.5 \%$ of the population are Tibetans, and the rest are Han or other minority groups ${ }^{[31]}$. To the authors' knowledge, merely a few studies published internationally have described the incidence rate, physiological mechanism, and therapeutic results of the infertility for the plateau inhabitants. One research paper suggested that native Tibetan males had higher incidence rates of azoospermia and severe oligozoospermia than the immigrant Han in Tibet ${ }^{[32]}$. Another study showed that the clinical manifestations of polycystic ovarian syndrome (PCOS) in Tibetan patients were significantly different from those of Han patients, and the prevalence of PCOS in Tibetan areas is slightly higher than in other regions ${ }^{[33]}$. In view of the extreme particularity of the geographical environment, demographical characters and ethnic differentials in Tibet, more target investigation should be meticulously designed and implemented, in order to better understand the needs and provide appropriate infertility treatments.

This study has certain limitations. First, it was assumed that if one or more ART clinics was located in a city, all residents in the city had access to ART services. Some factors, such as the great distance and high cost, that discourage people from utilizing fertility health care, were not taken into account. From this perspective, the estimation of 179.5 million reproductive-age population with no access to ART services may be lower than reality. On the contrary, some advanced ART clinics, located near the border of provinces, could attract patients from outside the province ${ }^{[24]}$. That might cause overestimation of people with limited accessibility. To better recognize and furthermore reduce the inequity in provision of ART services and lower the barriers utilization of those services, more endeavors in related research will be needed in future. This study has tried to offer a glimpse of the development and distribution of ART clinics in China by available empirical evidence. It is hoped that these results can serve as an impartial and objective benchmark for future policy making and assessment in China.

\section{Conclusion}

In conclusion, this study showed that the accessibility of ART clinics in mainland China has increased significantly in the previous twelve years. The equity of ART clinics distribution was quite balanced over the country based on the population index. However, underserved areas do exist, mostly in western China. Besides properly increasing the number of ART clinics, more cost-effective measures to improve the accessibility and availability of infertility prevention and health care should be given priority in underserved areas.

\section{Declarations}

Acknowledgments 
We would like to acknowledge the department of women and children health of National Health Commission of the China, and provincial departments of Health Commission for their support in data collection. We also thank R. Duncan Frewin for English language editing.

\section{Authors' contributions}

Yi Ma and Lina Gao collected publicly available data. Yi Ma performed the calculations and wrote the manuscript. Yanjun Fan, Fu Bai and Lina Gao reviewed the final article and made appropriate corrections and suggestions. Yanjun Fan did the final proof reading and confirmed the final version, as the paper's corresponding author.

\section{FUNDING}

The study was funded by the National Key Technology R\&D Program of China (2018YFC1002106).

\section{Availability of data and material}

The datasets used and/or analyzed during the current study are available from the corresponding author on reasonable request.

\section{Ethics approval and consent to participate}

Not applicable. (All data were taken from the publicly available sources. These were secondary data without any personal information, so informed consent was not needed.)

\section{Consent for publication}

Not applicable.

\section{Competing interests}

The authors declare that they have no competing interests.

\section{References}

1. Empel IWHV, Nelen WLDM, Tepe ET, Laarhoven EAPV, Verhaak CM, Kremer JAM. Weaknesses, strengths and needs in fertility care according to patients. Hum Reprod 2010; 25:142-9.

2. Quinn M, Fujimoto V, Racial and ethnic disparities in assisted reproductive technology access and outcomes. Fertil Steril 2016; 105: 1119-23.

3. Makuch MY, Simonia DPK, Petta CA, Duarte OMJ, Bahamondes L. Inequitable access to assisted reproductive technology for the low-income Brazilian population: a qualitative study. Hum Reprod 2011; 26: 2054-60.

4. Pennings G, Wert GD, Shenfield F, Tarlatzis CB, Devroey P. ESHRE Task Force on Ethics and Law 14: equity of access to assisted reproductive technology. Hum Reprod 2008; 23: 772-4. 
5. Rezaei S, Matin BK, Karyani AK, Pourreza A, Distribution of physicians and hospital beds based on Gini coefficient and Lorenz curve: A national survey. J Kermanshah Univ Med Sci 2016; 20: 30-6.

6. Ethics Committee of the American Society for Reproductive Medicine. Disparities in access to effective treatment for infertility in the United States: an Ethics Committee opinion. Fertil Steril 2015; 104: $1104-10$.

7. Harris JA, Menke MN, Haefner JK, Moniz MH, Perumalswami CR. Geographic access to assisted reproductive technology health care in the United States: a population-based cross-sectional study. Fertil Steril 2017; 107: 1023-27.

8. Dyer S, Chambers GM, Adamson GD, Banker M, Mouzon JD, Ishihara O, et al. ART utilization: an indicator of access to infertility care. Reprod Biomed Online 2020; 41: 6-9.

9. Warner L, Jamieson DJ, Barfield WD, CDC Releases a national public health action plan for the detection, prevention, and management of infertility. Journal of Women's Health 2015; 24: 548-9.

10. American Society for Reproductive Medicine. White paper: acess to care summit. Proceedings of the ASRM's Access to Care Summit; 2015 Sep 10-11; Washington. American Society for Reproductive Medicine, 2015: 1-67.

11. Yin $\mathrm{CH}, \mathrm{He} \mathrm{QS}$, Liu YF, Chen WQ, Gao Y. Inequality of public health and its role in spatial accessibility to medical facilities in China. Applied Geography 2018; 92: 50-62.

12. Qiao J, Feng HL. Assisted reproductive technology in China compliance and non-compliance. Tansl Pediatr 2014; 3: 91-7.

13. National Health Commission. Supplementary Provisions on Standardizing the Approval of Human Assisted Reproductive Technology and Human Sperm Bank. 2015. No. 56.

14. National Health Commission. Human Assisted Reproductive Technology Allocation Planning Guideline. 2015. No. 53.

15. Bai F, Wang DY, Fan YJ, Qiu J, Wang L, Dai Y, et al. Assisted reproductive technology service availability, efficacy and safety in mainland China 2016. Hum Reprod 2020; 2: 1-7.

16. National Health Commission. List of institutions which are approved for carrying out human assisted reproductive technology and setting up a human sperm bank. Available at: http://www.nhc.gov.cn/wjw/fzszjg/list.shtml. Accessed July, 2019.

17. Ministry of Civil Affairs of the People's Republic of China. Statistical Table of Administrative Divisions of China. Available at: http://xzqh.mca.gov.cn/statistics/2018.html. Accessed January, 2019.

18. Mobaraki H, Hassani A, Kashkalani T, Khalilnejad R, Chimeh EE. Equality in distribution of human resources: the case of Iran's minisitry of health and medical education. Iranian J Publ Health 2013; 42: 161-5.

19. Lu L, Zeng JC. Inequalities in the geographic distribution of hospital beds and doctors in traditional Chinese medicine from 2004 to 2014. Int J Equity Health 2018; 17: 165. 
20. Brown MC, Using Gini-style indices to evaluate the spatial patterns of health practitioners: Theoretical considerations and an application based on Alberta data. Soc Sci Med 1994; 38: $1243-$ 56.

21. Wang YY, Li YY, Qin SR, Kong YF, Yu XY, Guo KQ, et al. The disequilibrium in the distribution of the primary health workforce among eight economic regions and between rural and urban areas in China. Int J Equity Health 2020; 19: 1-10.

22. Sunderam S, Kissin DM, Zhang YJ, Folger SG, Boulet S, Warner L, et al. Assisted Reproductive Technology Surveillance-United States, 2016. MMWR Surveill Summ 2019; 68: 1-23.

23. Ishihara O, Jwa SC, Kuwahara A, Katagiri Y, Kuwabara Y, Hamatani T, et al. Assisted reproductive technology in Japan: a summary report for 2017 by the Ethics Committee of the Japan Society of Obstetrics and Gynecology. Reprod Med Biol 2020; 19: 3-12.

24. Nangia AK, Likosky DS, Wang DM. Access to assisted reproductive technology centers in the United States. Fertil Steril 2010; 93: 745-61.

25. National Health Commission. Technological Specification, Basic Standard and Ethical Principle Related to Human Assisted Reproductive Technology and Human Sperm Banks. 2003. No. 176.

26. Harris K, Burley H, McLachlan R, Bowman M, Macaldowie A, Taylor K, et al. Socio-economic disparities in access to assisted reproductive technologies in Australia. Reprod Biomed Online 2016; 33: $575-84$.

27. Chambers GM, Hoang VP, Illingworth PJ. Socioeconomic disparities in access to ART treatment and the differential impact of a policy that increased consumer costs. Hum Reprod 2013; 28: 3111-7.

28. Li X, Hu S, Cheng KK, Maeseneer JD, Meng QY, Mossialos E, et al. The primary health-care system in China. The Lancet 2017; 390: 2584-94.

29. Lei JB, Wen D, Zhang XT, Li JY, Lan HY, Meng Q, et al. Enabling health reform through regional health information exchange: a model study from China. J Healthc Eng 2017; 2017: e1053403.

30. Liang J, Zheng X, Chen ZY, Dai SQ, Xu J, Ye H, et al. The experience and challenges of healthcarereform-driven medical consortia and regional health information technologies in China: A longitudinal study. Int J Med Inform 2019; 131: e103954.

31. Liu JH, Larsen U, Wyshak G. Prevalence of primary infertility in China: in-depth analysis of infertility differentials in three minority province/autonomous regions. J Biosoc Sci 2005; 37: 55-74.

32. Gu BH, Liu F, Li J, Zhu ZJ, Li Z. Impact of plateau environment on seminal characteristics of native Tibetans and immigrated Tibetan Hans. Zhonghua Nan Ke Xue 2018; 24: 27-32.

33. Zhai KL, Zhuo G, Chi HB, Lan Z. Comparisons of prevalence and clinical and environmental characteristics between Tibetan and Han Women with polycystic ovarian syndrome in Tibetan Plateau. Zhonghua Yi Xue Za Zhi 2017; 97: 2928-31.

\section{Figures}




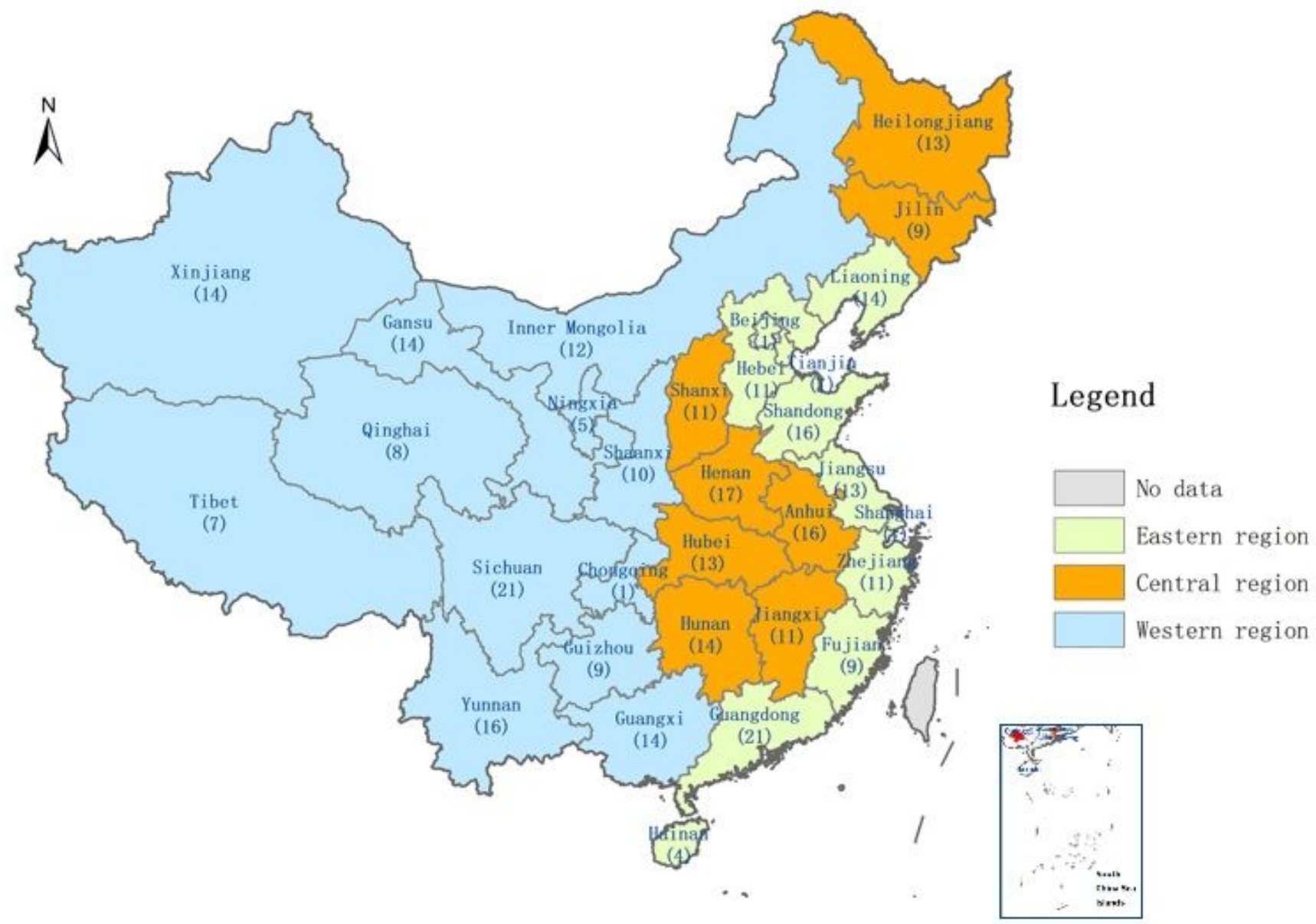

\section{Figure 1}

Number of cities in each province and regional division in China. Note: The designations employed and the presentation of the material on this map do not imply the expression of any opinion whatsoever on the part of Research Square concerning the legal status of any country, territory, city or area or of its authorities, or concerning the delimitation of its frontiers or boundaries. This map has been provided by the authors. 


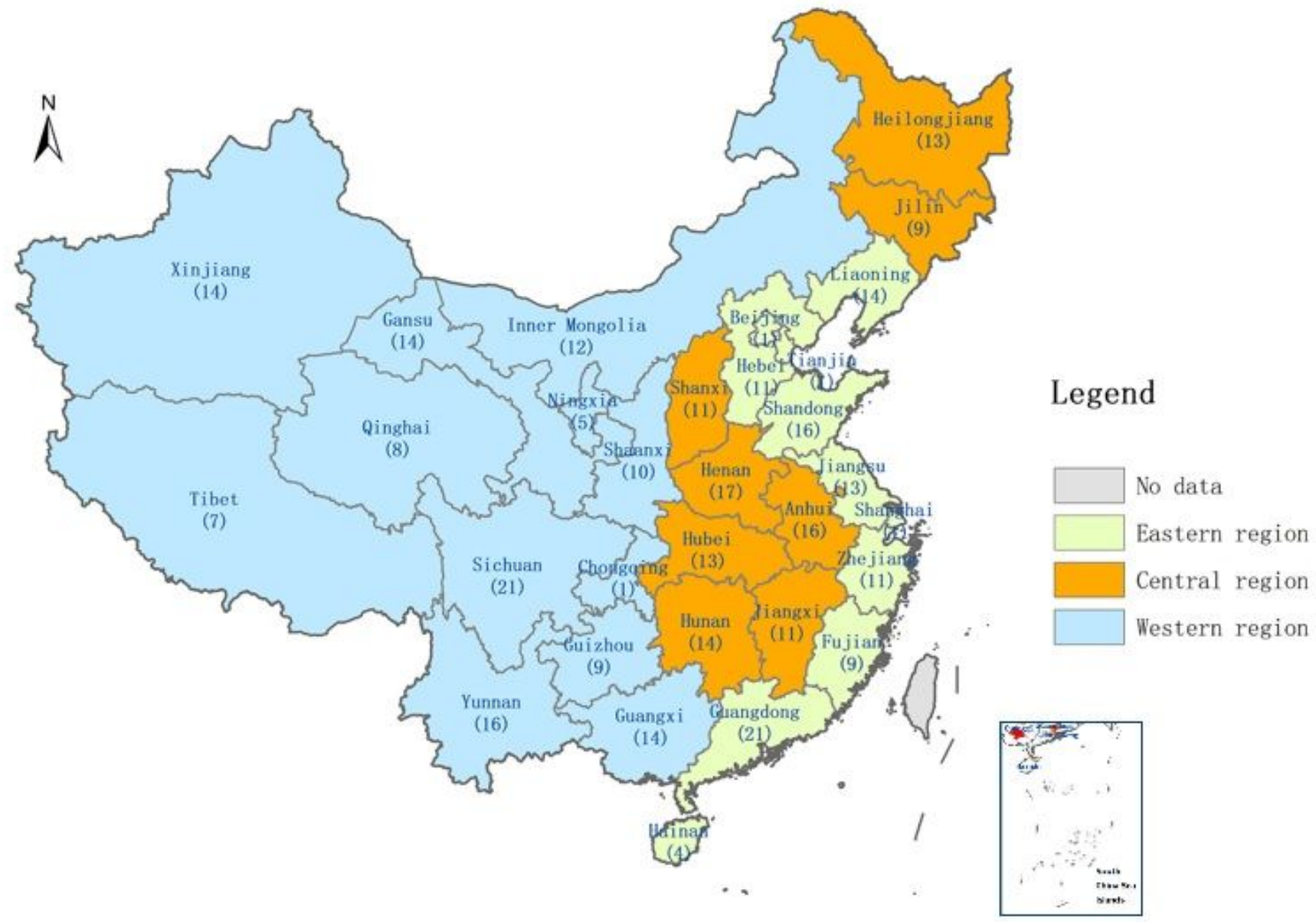

\section{Figure 1}

Number of cities in each province and regional division in China. Note: The designations employed and the presentation of the material on this map do not imply the expression of any opinion whatsoever on the part of Research Square concerning the legal status of any country, territory, city or area or of its authorities, or concerning the delimitation of its frontiers or boundaries. This map has been provided by the authors. 


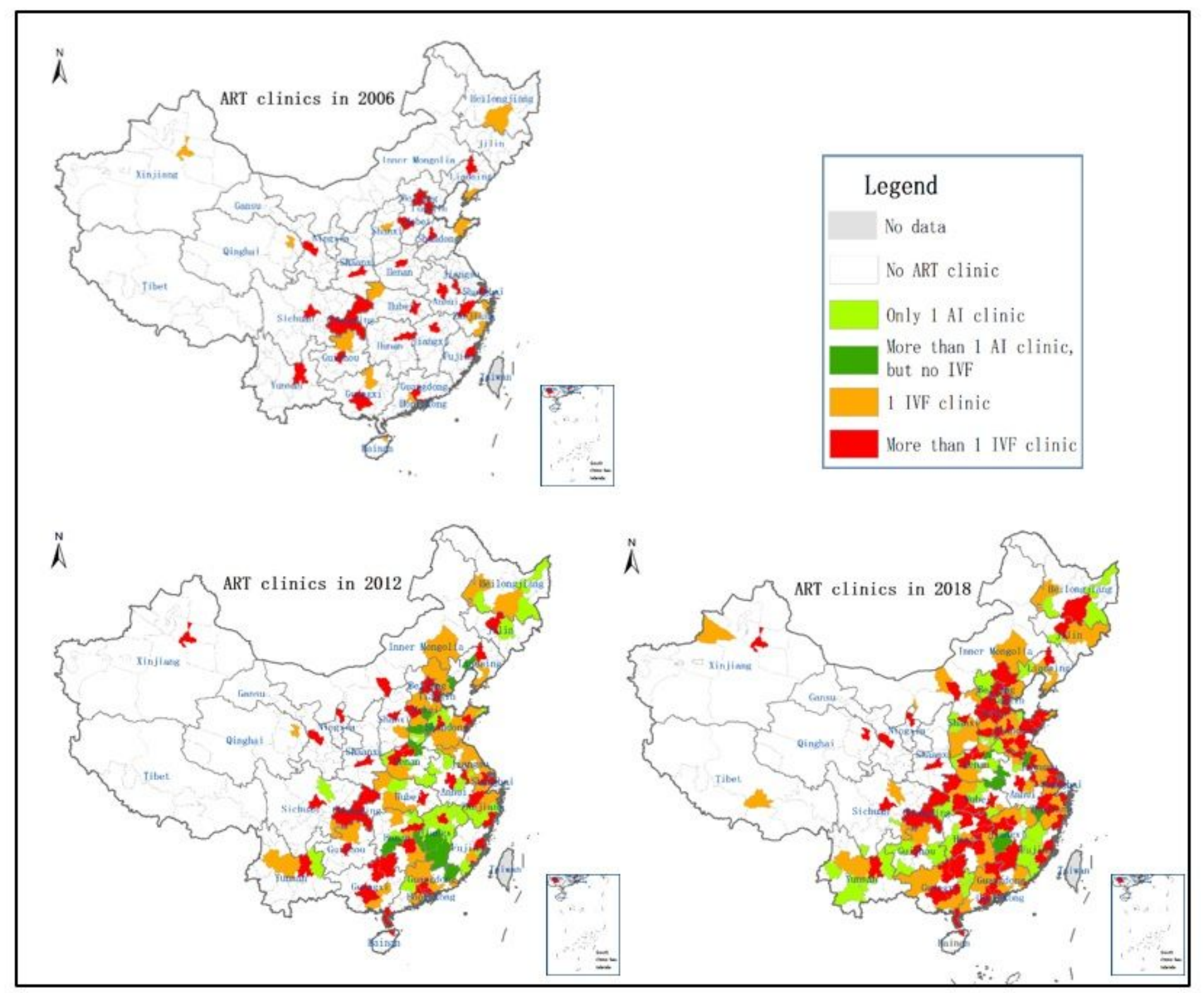

Figure 2

Map of China by regional access to ART in 2006, 2012 and 2018. The legend defines areas where cities have no ART clinics, only one AI clinic, multiple AI clinics without IVF, one IVF clinic, multiple IVF clinics. Each city is outlined in light grey. Each province is outlined in dark grey. Note: The designations employed and the presentation of the material on this map do not imply the expression of any opinion whatsoever on the part of Research Square concerning the legal status of any country, territory, city or area or of its authorities, or concerning the delimitation of its frontiers or boundaries. This map has been provided by the authors. 


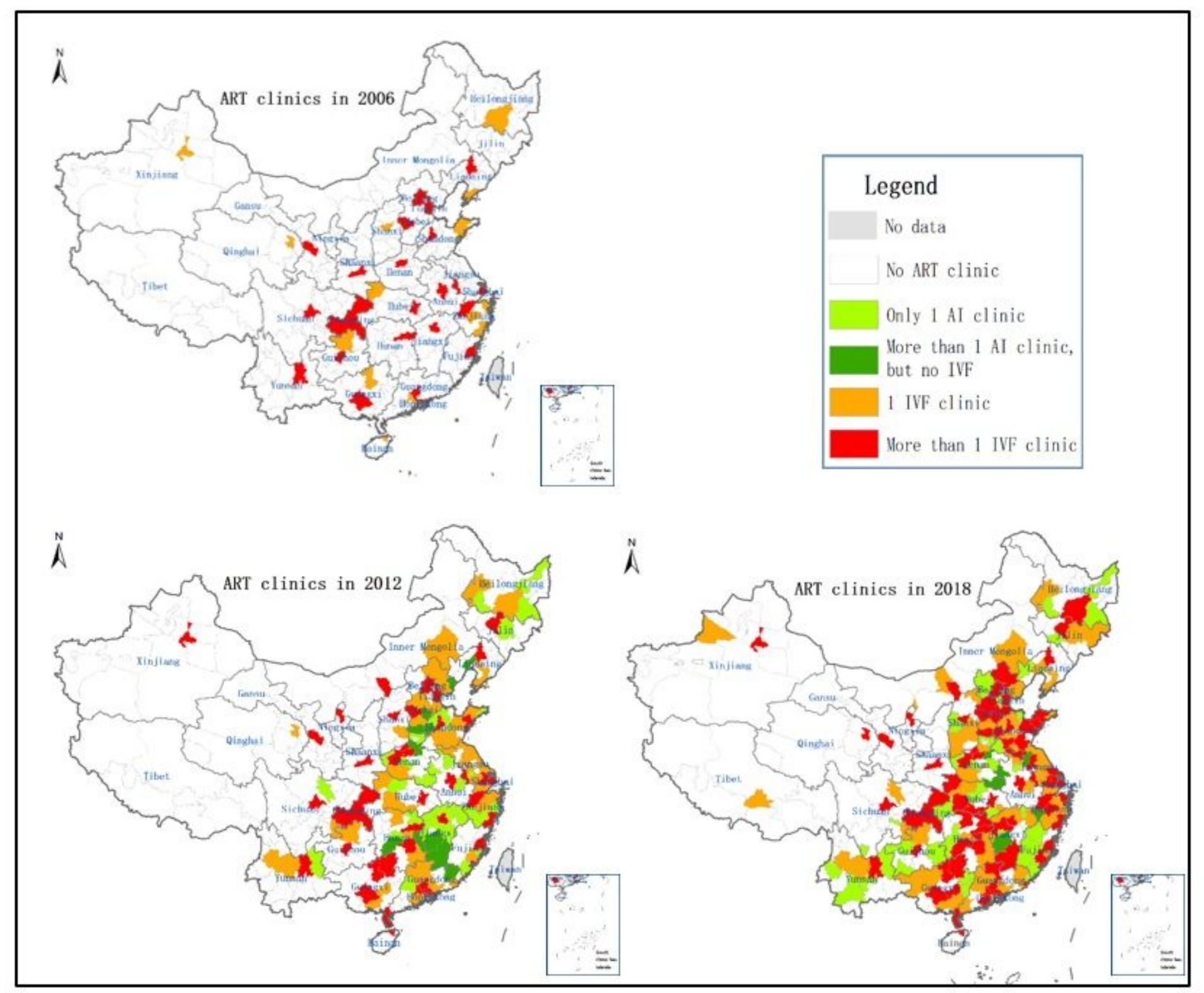

Figure 2

Map of China by regional access to ART in 2006, 2012 and 2018. The legend defines areas where cities have no ART clinics, only one AI clinic, multiple AI clinics without IVF, one IVF clinic, multiple IVF clinics. Each city is outlined in light grey. Each province is outlined in dark grey. Note: The designations employed and the presentation of the material on this map do not imply the expression of any opinion whatsoever on the part of Research Square concerning the legal status of any country, territory, city or area or of its authorities, or concerning the delimitation of its frontiers or boundaries. This map has been provided by the authors. 


\begin{tabular}{|c|c|c|c|c|c|}
\hline \multicolumn{6}{|l|}{0.4} \\
\hline \multicolumn{6}{|l|}{0.3} \\
\hline \multicolumn{6}{|l|}{0.2} \\
\hline 0.1 & & & & & \\
\hline 0.0 & 2006 IVF & 2012 IVF & 2018 IVF & 2012 ART & 2018 ART \\
\hline All & 0.389 & 0.275 & 0.267 & 0.222 & 0.213 \\
\hline Eastern & 0.389 & 0.231 & 0.198 & 0.152 & 0.157 \\
\hline Central & 0.279 & 0.248 & 0.216 & 0.126 & 0.138 \\
\hline Western & 0.276 & 0.182 & 0.257 & 0.228 & 0.228 \\
\hline
\end{tabular}

Figure 3

Gini coefficients for distribution of ART/IVF clinics in China based on population. 


\begin{tabular}{|c|c|c|c|c|c|}
\hline 0.4 & & & & & \\
\hline 0.3 & & & & & \\
\hline 0.2 & & & & & \\
\hline 0.1 & & & & & \\
\hline 0.0 & 2006 IVF & 2012 IVF & 2018 IVF & 2012 ART & 2018 ART \\
\hline All & 0.389 & 0.275 & 0.267 & 0.222 & 0.213 \\
\hline Eastern & 0.389 & 0.231 & 0.198 & 0.152 & 0.157 \\
\hline Central & 0.279 & 0.248 & 0.216 & 0.126 & 0.138 \\
\hline Western & 0.276 & 0.182 & 0.257 & 0.228 & 0.228 \\
\hline
\end{tabular}

Figure 3

Gini coefficients for distribution of ART/IVF clinics in China based on population.

\section{Supplementary Files}

This is a list of supplementary files associated with this preprint. Click to download.

- Supplementaltable1.docx

- Supplementaltable1.docx 